\title{
Context or culture: what is the difference?
}

\author{
Isabelle Savard ${ }^{1 *}$ (D) and Riichiro Mizoguchi ${ }^{2,3}$
}

\footnotetext{
*Correspondence: isabelle.savard@ teluq.ca

'TÉLUQ University, 455 Du Parvis, Québec G1K 9H6, Canada Full list of author information is available at the end of the article
}

\begin{abstract}
Literature can sometimes tend to present context and culture almost as synonyms. This creates ambiguity, which can complicate the consideration of contextual and cultural variables in instructional design, learning, and teaching. From an ontological point of view, some clarification of these two concepts is essential as each may influence learning and teaching in different ways. Moreover, since context and culture are interconnected to a certain degree, one may influence the other. It is crucial to make a clear distinction between these two concepts in the knowledge models used in intelligent tutoring systems and distance education systems if we want to facilitate (1) their consideration in pedagogical scenarios, and (2) the accumulation of knowledge about different contexts and cultures. This article offers an interpretation of the difference between these two concepts, presenting context as a substrate of culture. Contextual issues in the learning ecology are also discussed, based on this distinction.

Keywords: Context, Culture, Ontology, Learning ecology, Instructionnal design
\end{abstract}

\section{Introduction}

The need for adaptation and flexibility in pedagogy is more urgent than ever (Bates and Sangra, 2011; Collis and Moonen, 2012; Edmundson, 2007; Gros and Maina, 2015; Maina and González, 2016; Rogers, Graham, and Mayes, 2007; Subramony, 2011, 2017; Williams, Karousou, and Mackness, 2011). The integration of international dimensions within instructional programs now applies to everyday pedagogical life. This concerns the international mobility of learners, teachers, and researchers, but also the integration of international, intercontextual, and intercultural dimensions in training programs, at all levels, from primary school to higher education and continuing professional development. This means that we all have to consider, consciously or not, contextual and cultural variables. But are we equipped to do so? In what ways can clear distinctions between the context and the culture be made, in order to use them explicitly to improve learning?

Bazire and Brézillon (2005) noted that the word "context" is either not defined or is defined in multiple ways. They explained this by the fact that this word is either used assuming that everybody knows its meaning, or to delineate the particular meaning the author gives to this word.

In the various definitions, two broad categories are often mentioned: definitions that see the context as internal to the individual and those that see it as being external. The first category views (internal) context as mental representations of an individual that 
could impact the learning process. The second interprets (external) context as environmental or circumstantial, and also having the potential to impact the learning process.

Brézillon (2002) stressed that the lack of an operational definition of context "explains several failures noted in knowledge-based systems use because (1) users and their contexts are not taken into account, (2) out of its context of validity, there is an incorrect use of the knowledge, (3) with the infinite number of contexts, it is not possible to endow a system prior to its use with all the needed knowledge, ..." . This is to say that, without this operational definition, it is difficult to consider the contextual variables in instructional design and to facilitate the accumulation of knowledge about context. The consideration of those variables may improve learning. For example, according to Gilbert, Bulte, and Pilot (2011), "context-based courses" are increasingly used to address the major challenges that science education currently faces: lack of clear purpose, content overload, incoherent learning by students, lack of relevance to students, and lack of transfer of learning to new contexts."

Savard (2014) highlighted the large number of definitions of culture. After an analysis, she formulated such a definition, inspired by that of Spencer-Oatey (2004). She sees culture as a set of schemes, shared by a given group. This definition has been adopted by Savard and Mizoguchi (2016) and reused in this project. It is presented in Section 2 below.

We believe that e-learning, combined with the use of various technologies, including those derived from artificial intelligence (AI) (e.g., ontological engineering ${ }^{1}$ ) and data analysis (e.g., educational data mining) (Leitner, Khalil, and Ebner, 2017; Maseleno et al., 2018), which open the door to behavioral prediction and adaptability of training content, provides excellent opportunities for the integration of learning transfer and adaptation concerns. The many online tools for sharing and collaboration provide so many opportunities for exchanges, meetings, and transfers that sometimes there is a sense that distance is bringing us closer. These opportunities generate vast bodies of data whose collection and analysis can provide indicators of pedagogical interest. A clear and explicit distinction between context and culture in the knowledge models used in intelligent tutoring systems (ITSs) and distance education systems (DES) is crucial if we want to facilitate (1) their consideration in pedagogical scenarios (for teaching and learning), and (2) the accumulation of knowledge about different contexts and cultures, in order to use it to improve learning and teaching. As highlighted by Mizoguchi (2003), to discuss such fundamental concepts (as culture and context), we need to do an in-depth analysis of them. It requires a comprehensive understanding of related issues in order to grasp the essentials about them. Chandrasekaran, Josephson, and Benjamins (1999) concur, explaining that "without ontologies, or the conceptualizations that underlie knowledge, there cannot be a vocabulary for representing knowledge. Thus, the first step in devising an effective knowledge representation system, and vocabulary, is to perform an effective ontological analysis ...." Ontology engineering

\footnotetext{
${ }^{1}$ According to (Gruber, 1993), an ontology is an explicit specification (interpretable by the computer) of a conceptualization. A conceptualization is an abstract, simplified view of the world we wish to represent, a description of the concepts and relationships that may exist between them for an agent or a community of agents. We sometimes use the term "model [explicit]" to refer to an ontology or a formal conceptual map (i.e., one that is computer-interpretable).
} 
provides us with a theory of content and a technology for dealing with content independently of the domain, and it enables us to discuss these concepts properly.

This article offers an interpretation, using an ontology engineering approach, of the difference between these two concepts, presenting context as a substrate of culture, which means that it serves as a support for culture.

\section{Method}

We have used the graphical ontology editor Hozo described in Mizoguchi, Sunagawa, Kozaki, and Kitamura (2007).

We first built on our previous work: Savard (2014) used a design-based research (DBR) iterative approach to identify cultural variables in the instructional design professional culture and modeled knowledge regarding these variables via a formal ontology on the basis of which a "Cultural Diversity" knowledge base has been created. The "Cultural Diversity" knowledge base brings together knowledge regarding five cultures. Savard developed an advisor system, presented in Savard, Paquette, and Bourdeau (2014) which, through an executable assistance process for cultural adaptation, uses this knowledge to advise the instructional designer, who then proceeds to adapt a pedagogical scenario to a culture other than his or her own. Hayashi, Bourdeau, and Mizoguchi (2009) elaborated the ontology of education called Omnibus, which establishes a multi-paradigm conceptual basis for learning/instructional theories to be used in a theory-aware and standard-compliant authoring system. Mizoguchi (2010) presented YAMATO as an upper ontology that "sharply distinguishes itself from other existing upper ontologies in the following respects. (1) Most importantly, Yamato is designed with both engineering and philosophical minds. (2) Yamato is based on a sophisticated theory of roles, given that the world is full of roles. (3) Yamato has a tenable theory of functions that helps to deal effectively with artifacts. (4) Information is a "content-bearing" entity and differs significantly from the entities that philosophers have traditionally discussed. Taking into account the flood of information that occurs in modern society, Yamato has developed a sophisticated theory of informational objects (representations). (5) Quality and quantity are carefully organized for the sake of greater interoperability of real-world data. (6) The philosophical contribution of Yamato includes a theory of objects, processes, and events."

We carefully analyzed these existing and validated ontologies in order to remain consistent with the vocabulary for representing knowledge and with the established relationships between concepts. A parallel was drawn between the vocabulary used in those three ontologies, and some decisions were made following a discussion among researchers when inconsistencies were identified, and there was a need to choose one term over another. As suggested by (Chandrasekaran et al., 1999), we wanted to ensure that the terminology enables the ontology to be coherent and cohesive for reasoning purposes. We then worked iteratively on the ontology, presenting context and culture and the relationships between the two concepts, alternating between discussions among researchers and experts in the field, literature reviews, and automatic tests for coherence and cohesiveness available in the Hozo ontology editor.

\section{An ontological view of the difference between context and culture}

Savard and Mizoguchi (2016) present an upper ontology of culture in which they have modeled knowledge according to a procedural approach. Such an approach allows for 
making explicit the functionalities of culture and opens a door to concrete and practical solutions for cultural adaptation in ITSs and DES. Logically, in the course of this research, modeling of the context became necessary. This article presents an ontological view of the differences and complementarities between context and culture.

As in Savard and Mizoguchi (2016), culture here is defined as "an evolving (in both time and space) cognitive structure composed of such schemes that influence the behavior of each of the members of a given group, the manner in which the members of the group interpret the behavior of other persons and groups, and the processes of interpretation and representation that allow them to interact with their environment." As illustrated in Fig. 1, culture has the attribute of being shared by a group of persons and consists of interpretation and manifestation schemes. As it will be explained in Section 3.2 , the same individual is usually influenced by different cultures.

Context, as represented in Fig. 1, refers to the external context briefly described in the introduction. This context may be defined as the set of circumstances that frames an event or an object, including the following: one or more agents that have the role of being participants, one or more environments, one or more events, and one focus entity that can be the role holder $(\mathrm{RH})^{2}$ participant or the event, through which it enables the framing operation that manages to attach the appropriate circumstances to itself. Each of these elements will be explained in more detail in Section 3.1 below.

In the same procedural approach, in order to analyze the functionalities (of context and culture) and to open the door to concrete and practical solutions for adaptation, context is represented here as a substrate, meaning that it serves as a support for some-

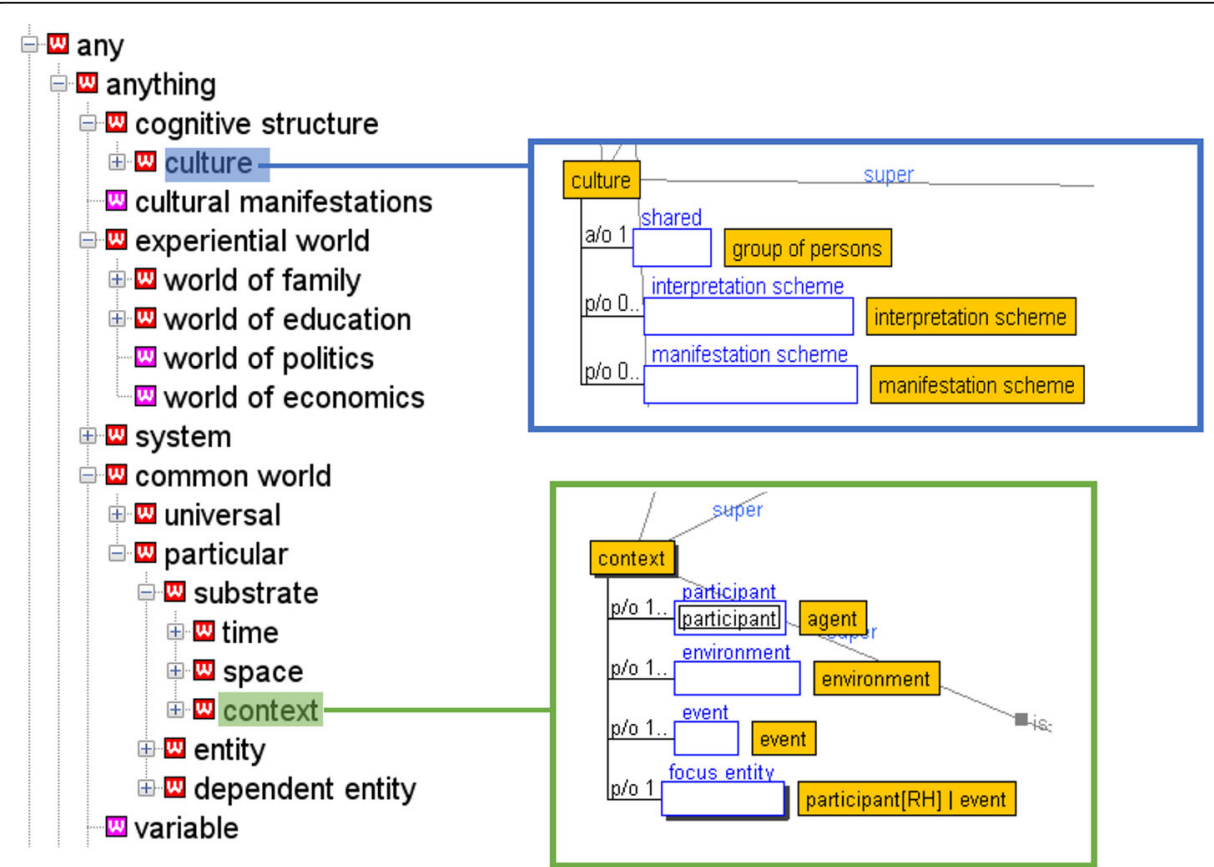

Fig. 1 Culture and context in the upper ontology. a/o, attribute of; p/o, part of

\footnotetext{
${ }^{2}$ The expression "role holder" is used here as defined in Mizoguchi et al. (2007), as an entity who/which is playing a role. For example, in a given context, there is a potential player who plays a role, and when the player plays it, then he/she becomes a role holder.
} 
thing else to exist, such as culture. That is to say, we use our cultures IN contexts and the intensity of their influence may vary according to the context. It is only in context that culture has an influence. Without the context, culture has no concrete influence, only a potential influence. It will be discussed in the following sections.

Figure 1 also shows that a "common world" has been defined. This part of the work has been done based on the "common world" described in Omnibus, the ontology of education presented by Hayashi et al. (2009). In this world, concepts are represented that are common to all cultures, for example the concepts of time or space.

As humans, we evolve in a variety of other "worlds," each having their own particularities. They are represented in Fig. 1 under the label of "experiential world." Examples shown in this figure are the world of family, world of education, world of politics, and world of economics. These are worlds where we live different experiences and that generally incorporate a subculture, i.e., a particular "evolving (in both time and space) cognitive structure composed of such schemes that influence the behavior of each of the members of this given group (in relation with the specific experiential world), the manner in which the members of the group interpret the behavior of other persons and groups, and the processes of interpretation and representation that allow them to interact with their environment" (Savard and Mizoguchi, 2016). This will be explained in greater detail in Section 3.2 below.

Firstly, the concept of context will be discussed in depth. Then, the concept of culture will be explained in relation to context.

\section{Model of context}

Figure 2 shows that (external) context can be generic or specific. While the generic tends to be more neutral, the specific context is situated in space and time. This figure

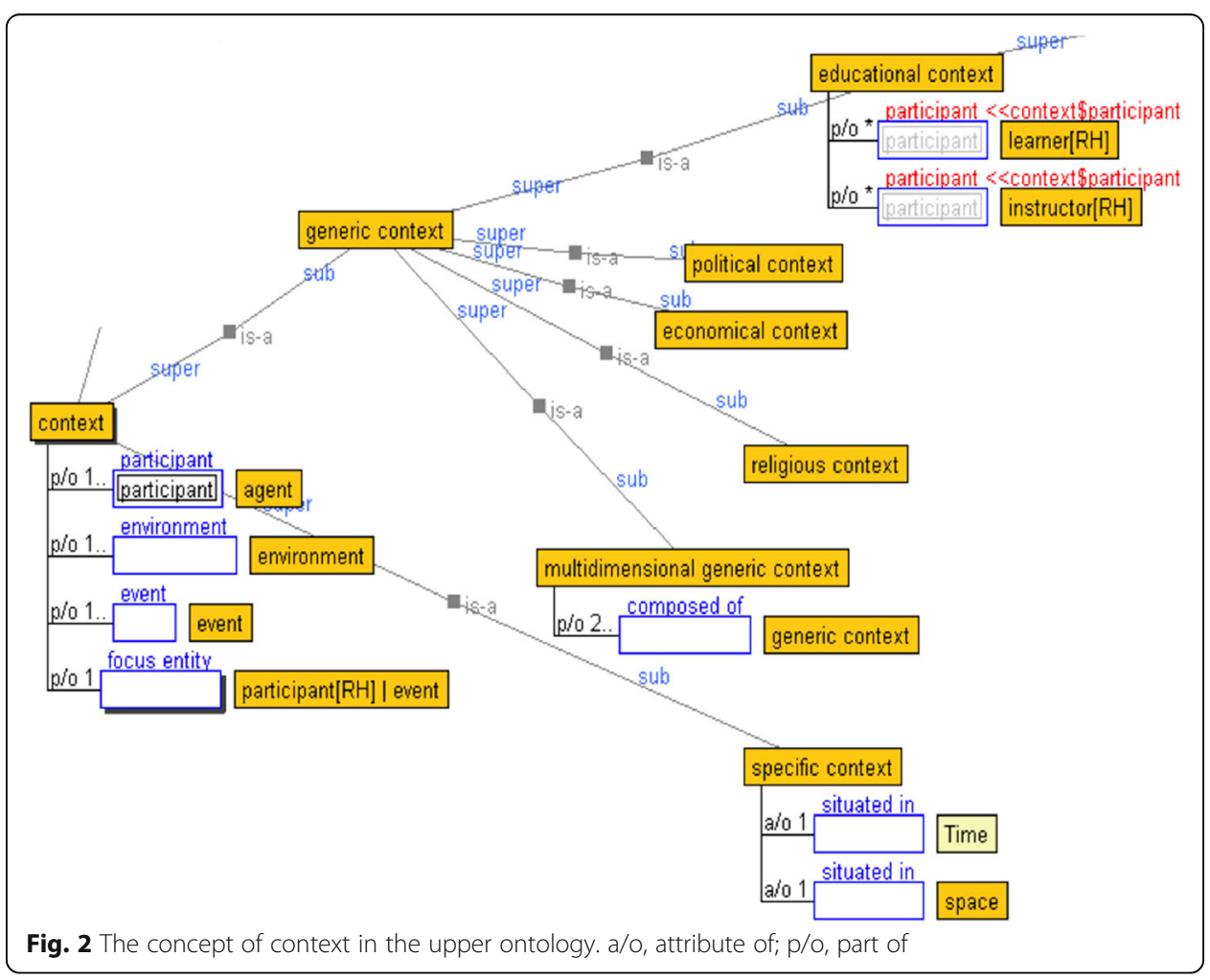


also shows, as defined earlier in this article, that the context includes the following elements: one or more agents that have the role of being participants, one or more environments, one or more events, and one focus entity. When all the information is available, context can be planned in advance, but it can also be unpredictable (Bazire and Brézillon, 2005) and can be defined as and when required. In all cases, context can be the substrate of culture. Both context and culture are dynamic and evolving.

The following paragraphs briefly describe the different elements (p/o) of context represented in Fig. 2.

An agent, which is an element of context, can be singleton or complex. A singleton agent can be artificial (e.g., a robot) or natural (e.g., a human being). As explained earlier, every human being is influenced by different cultures. A group can be considered a complex agent.

An environment can be virtual (e.g., online learning platform), hybrid or physical (e.g., classroom, practice field). The environment is generally created by humans (influenced by their cultures).

An event has a participant and an action. The concept of action is central here. Bazire and Brézillon (2005) analyzed 150 definitions of context in order to identify the main components of context. They concluded that many of these definitions "concern the context of a behavior, the behavior being an action or a cognitive activity (decision, problem solving, or representation construction)." As mentioned earlier, it is precisely in relation to action (or cognitive activity) that the context can be considered the substrate of culture. Indeed, it is in and on action that culture has an influence.

In our model, partly shown in Fig. 3, the action is represented in the event, which is an element of the context.

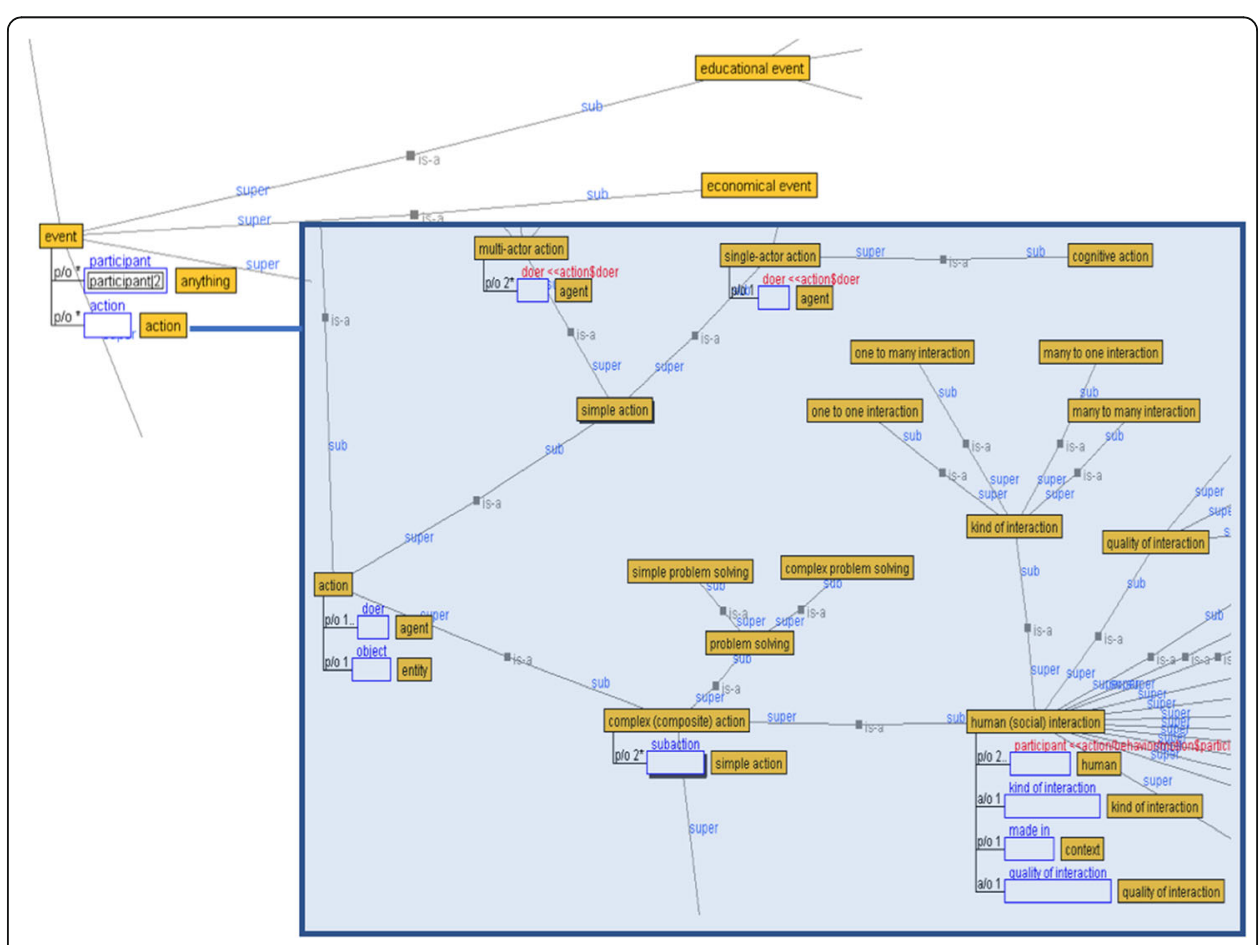

Fig. 3 The action as part of the event, which is part of the context. a/o, attribute of; p/o, part of 
Figure 3 illustrates that an action can be simple or complex. Among the simple actions is the single actor action involving a doer agent. Cognitive action is a kind of single-actor action. Complex actions involve two or more simple actions as subactions. Problem solving is a kind of complex action as well as a human (social) interaction that occurs in context (as represented in Fig. 2).

Finally, as was explained earlier about the focus entity, a context is determined by collecting entities relevant to a focus entity, since a context must be an entity FOR something. It cannot be independent of "something." For example, a singer sings songs in a concert event. The singing action is performed in the context of the concert, which consists of many actions performed by the audience and staff members who support the concert. If we do not focus on the singing action, the concert event is just an event and it is not a context. When students learn in a lesson event in a class, the learning action is accomplished in the context of the lesson, whereas if we do not focus on the learning action, the lesson is just an event. A context cannot be just anything on its own. A context emerges only when we focus on an entity. Gilbert et al. (2011) approach this idea and discuss context as being "formed around some focal event-an important or typical event-that draws the attention of the learners."

\section{Model of culture}

As humans, we are not influenced by only one culture. We all have different sets of schemes that influence our behavior, our interpretation of other people's behaviors, and processes of interpretation and representation that allow us to interact with different environments (professional, sports, leisure, etc.). These different sets of schemes are subcultures. As shown in Fig. 4, every human agent (participant in context, in Figs. 1 and 2) has a cultural configuration that includes a main culture and different subcultures (for example, "Canadian" could be someone's main culture and instructional design for one of his/her (professional) subcultures).

It is essential to model the cultural configuration because groups also have their own cultural configuration. In fact, the cultural configuration of a group is not necessarily

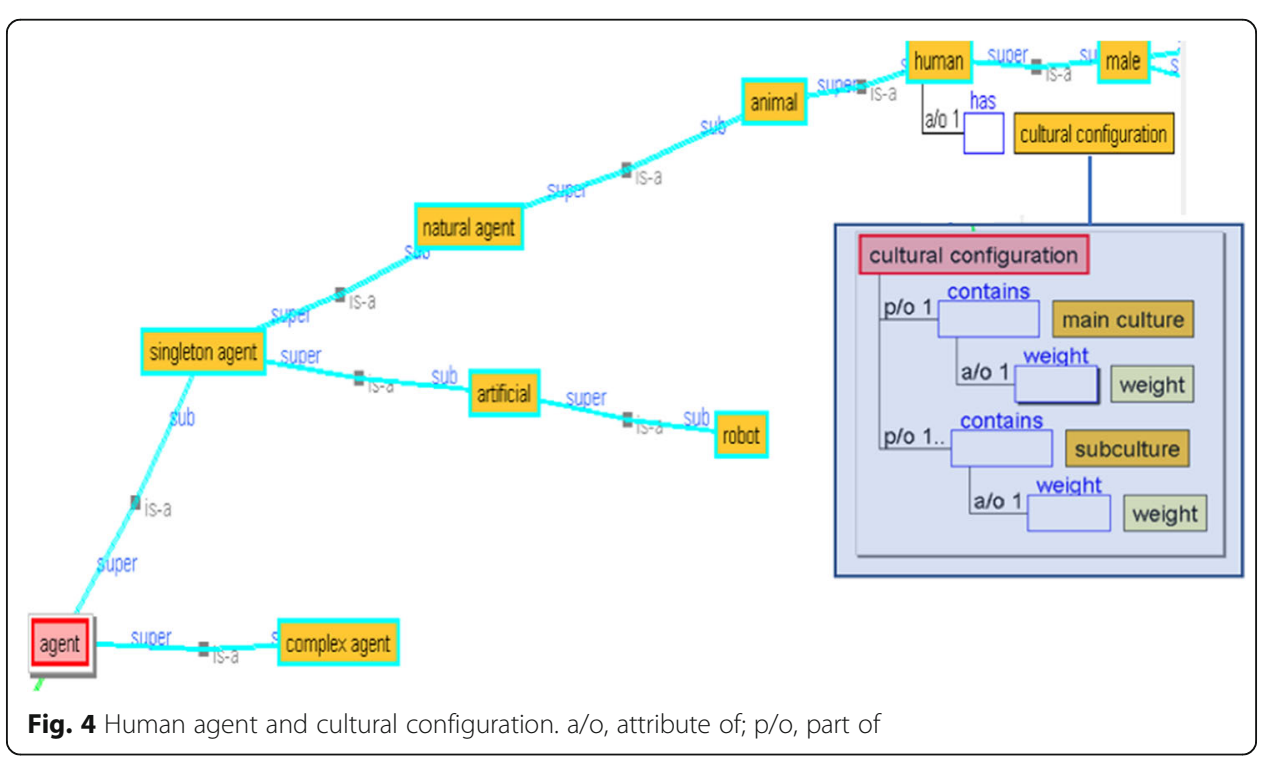


the sum of the cultural configurations of the individual humans who make up the group. For example, in an international working group of instructional designers, the professional culture will probably have more weight than the national cultures of the participants, who will adapt to each other and also to the context (as represented in Fig. 2) in which the group is working. So, culture can influence context and the reverse is also true: context can influence culture. Subcultures can be quite ephemeral and "exist" for the time it takes to complete a project.

Figure 5 shows in more detail the distinction between main culture and subcultures. Main culture has some influence on subcultures and experiential worlds, and each subculture influences the experiential world to which it is attached. The reverse is also true: the experiential world can influence the subculture. All of this is dynamic, as represented below, and these are systems that interfere with each other.

We believe that for individual human beings, main culture is often the national culture, the one in which they grew up, the one used by their parents to educate them. Of course, as illustrated in Fig. 5, the main culture could be Métis and be composed of more than one culture (such as when one parent is from one culture, let us say Japanese, and the other parent is from another culture, Canadian for example). The idea here is to allow the model to take into consideration the weight of the different cultures and subcultures that can influence more or less strongly behaviors, the interpretation of behaviors, and the processes of interpretation and representation.

This cultural configuration will be adjusted according to the context. The group or the individuals will adjust according to the context. For example, when I am interacting with my family, the subculture of the World of family has a higher weight. I can assume that the individuals with whom I interact (and with whom I have many cultural references in common) will understand my references to events or expressions without me having to explain them. But when I interact with a new Japanese friend, I cannot use the same references without explaining them, I cannot take for granted that my friend adopts the same rules of politeness, and I must provide or ask for explanations. Depending on the context (and the agent or action, which are part of the context), our

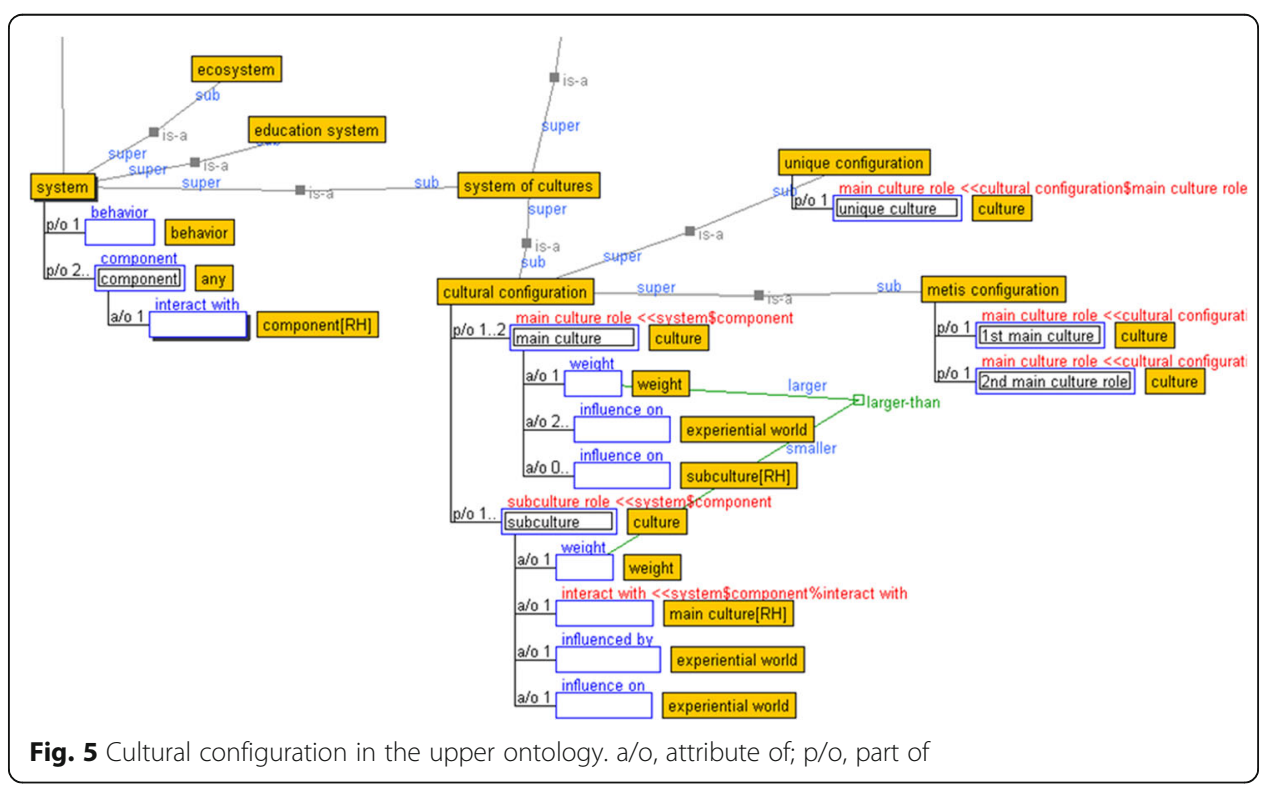


cultural configuration is adjusted. Understanding and distinguishing between the two concepts is essential to their full synergistic potential use. This distinction can help to avoid wasting time trying to solve a problem by adjusting contextual (external) elements when it is the cultural configuration that requires adjustments. Obtaining clear "External Parameters" and "Internal Parameters" requires the clear differentiation between contextual (external) and cultural (internal) matters. By recognizing context as the substrate of culture, we recognize the functions and potential roles of each (context and culture) in teaching and learning, and we broaden the horizon of possibilities for effective transfers and deeper learning. We make sure not to use both concepts as if they were synonyms and to create a harmful ambiguity. We enable ourselves to use both, context and culture, in their full synergistic potential of use.

\section{Discussion}

Distance learning, especially online learning, combined with the use of varied technologies, offers beautiful opportunities to use a variety of contexts to improve learning. In educational programs aiming at competencies development, competency is seen as a complex know-how, tied to action, that brings learners to mobilize their internal resources (knowledge, skills, attitudes) and external resources (colleagues, reference tools, books, etc.) within a family of situations (Tardif, 2006). To be considered competent, learners must demonstrate their complex know-how in different contexts. They need to make the transfer from one context to another. Tardif and Meirieu (1996) explain that "the transfer occurs when acquired knowledge [or developed competency] in a particular context can be reused wisely in a new context, i.e., when it can be recontextualized." Online learning is a way of bringing together learners who want to develop the same competencies, but who evolve in different (external) contexts. We believe that it offers great opportunities for contextualization-decontextualization-recontextualization, which are great opportunities to improve learning. In fact, it offers learners the opportunity to go back and forth between different external contexts and their internal context (mental representations). This is also fundamental for teachers who develop contextually and/or culturally aware ITSs or other teaching and learning systems. In fact, culture mostly works as the internal context for humans (learners, teachers, or instructional designers). But it can be confusing in some cases. For instance, when an ITS developed in Canada is deployed in Japan, people might say it would not work well because of the difference between cultures. They may think that culture is an external context in which the ITS is deployed. But this is not the case. It is the issue of ITS design that is considered to be the author/teacher perspective (related to her/his internal context). The reason why such a Canadian ITS might not work in Japan is not because culture functions as an external context, but because it works as an internal context in learners. Making both cultural and contextual variables explicit may eliminate some ambiguities that may affect the quality of teaching and learning.

Blanchard, Mizoguchi, and Lajoie (2010); Edmundson (2007); Savard, Bourdeau, and Paquette (2008); Savard et al. (2014); Young (2008); and others have already emphasized the importance of considering culture in those environments where diverse learners learn together with a variety of teachers.

We believe that models of context and culture have to be integrated into the traditional ITS architecture and, eventually, into knowledge-based systems connected with 
or integrated into digital learning environments. There are two main ways to use these models: the more traditional way, through meticulous use of knowledge already represented according to pre-established parameters, or by using them as a foundation for emergence. Williams et al. (2011) "have mapped out the characteristics of emergent learning and situated it within learning as a whole, distinguishing it from more traditional modes of learning in order to provide the basis for integrating both of these two modes of learning within an overall learning ecology." They demonstrated that "there is a need for a shift from a monolithic learning environment in which everything must be controlled and predictable to a more pluralistic learning ecology in which both prescriptive and emergent application domains and modes of learning have their place, and in which it is possible to celebrate the unpredictable." An architecture that would integrate ontologies as the basis for models of learners, domain, pedagogy, context, and culture, in combination with the use of a variety of tools, could favor the establishment of such pluralistic learning ecologies.

In such an approach, it seems vital to involve learners more, as they can provide information about the different models (learners, domain, pedagogy, contexts, culture), both in their learning and in planning their lifelong learning paths. Portfolios and collaborative instructional design environments could be some of the constructive solutions that could use and evolve these new models, but we need more research to offer a variety of complementary tools, and to be able to make more efficient and explicit use of culture and context models. As highlighted by Basque (2004, p. 70), the contextual perspective postulates that cognition and sociocultural background cannot be considered separately, and so this perspective proposes a different level of analysis. Here we are interested in the study of systems in interaction, that is, cognitive agents interacting with each other, and with physical and symbolic systems. It offers many worthwhile avenues for research.

By clearly distinguishing and explicitly defining the context and culture, it will be possible to develop knowledge bases on different contexts and cultures that can be used, separately or simultaneously, to benefit learning. Training in the health sciences is a good example, particularly in the context of chronic pain where the need for flexibility and adaptability in training is glaring and clearly transversal, both for patients and the various professionals involved. Specialists, teachers, and clinicians are called upon to train learners and treat patients from diverse backgrounds (social, cultural, etc.), and need to adapt training and approaches accordingly. Projects involving the application of person-centered approaches (Côté and Hudon, 2005; Stewart, 2003) are increasing. Learners, teachers, and clinicians must develop new competencies and equip themselves to take into account a diversity of contexts and cultures, and use this diversity to foster transfers that enhance learning, and interprofessional and intercontextual practice. In the field of health sciences, by emphasizing the importance of interprofessional practice, we encourage future practitioners to consider a variety of professional cultures and practice contexts, and diverse personal life contexts of patients. Thus, there is a definite interest in accommodating this diversity in curricula and in integrating these concerns for knowledge transfer and adaptation into teaching and learning practices. We need to find ways and to develop tools that will help us to actually achieve this. We need to manage this complexity and take advantage of diversity to benefit learning. 


\title{
Conclusion
}

We consider the explicit models (ontologies) proposed in this article to be a good starting point, consistent with the first step in devising an effective knowledge representation system and vocabulary, as proposed by Chandrasekaran et al. (1999). Such models provide a solid foundation for the consideration of contexts and cultures (in their full synergistic potential of use) in pedagogical scenarios (for teaching and learning), and for the accumulation of knowledge about different contexts and cultures, in order to use it to improve learning and teaching and to facilitate transfers. These models must now be used and tested in different contexts in order for them to be improved iteratively and made generally usable. Our first identified use context is within a training platform to address clearly identified training needs for chronic pain treatment.

\section{Abbreviations}

DES: Distance education systems; ITS: Intelligent tutoring systems; $\mathrm{RH}$ : Role holder

\section{Acknowledgements}

The authors thank Mary Eady for the linguistic revision of the manuscript.

\section{Authors' contributions}

IS had the original idea of the work; she led the ontological engineering work. She wrote the manuscript. RM participated in the ontological engineering work. He reviewed and commented on the manuscript. Both authors read and approved the final manuscript.

\begin{abstract}
Authors' information
Isabelle Savard is a professor at TÉLUQ University since January 2017 and she is the director of educational technology and distance learning programs. She completed her master's in educational technology at Laval University in 1996. Since then, she has worked as an educator and technology integration coordinator in Zambia (Africa), as an instructional designer and pedagogical advisor at the Centre for e-Learning at the University of Ottawa and in the Faculty of Medicine at Laval University, as a research assistant at the LICEF Research Centre (TÉLUQ). She holds a doctorate in cognitive informatics; her thesis is entitled "Modélisation des connaissances pour un design pédagogique intégrant les variables culturelles." She completed her doctoral research field work at the Virtual Center for Innovative Learning and Technologies (VCILT) at the University of Mauritius, where she observed and analyzed instructional design practices. She completed in 2016, a post-doctorate at the Japan Advanced Institute of Science and Technology (JAIST), in Japan. She works on tools to help instructional designers, teachers, and learners to deal with contextual and cultural variables and to enable flexible instructional design.

Riichiro Mizoguchi received Ph.D. degrees from Osaka University in 1977. His research interests include non-parametric data analyses, knowledge-based systems, ontological engineering, and intelligent learning support systems. He has been intensively involved in organizing many international conferences as Conference chairs, Program chairs, and Program committee members. Dr. Mizoguchi was President of International Al in Education Society and Asia-Pacific Society for Computers in Education from 2001 to 2003 and President of Japanese Society for Artificial Intelligence (JSAl) from 2005 to 2007. He was Vice-President of SWSA (Semantic Web Science Association) and Co-Editor-in-Chief of J. of Web Semantics from 2005 to 2009 and from 2008 to 2011, respectively. He is currently associate editor of ACM TiiS and an editorial board member of some international journals such as Applied Ontology.
\end{abstract}

\section{Funding}

No funding.

Availability of data and materials

Not applicable.

Competing interests

The authors declare that they have no competing interests.

\section{Author details}

${ }^{1}$ TÉLUQ University, 455 Du Parvis, Québec G1K 9H6, Canada. ${ }^{2}$ Research Center for Service Science, Japan Advanced Institute of Science and Technology (JAIST), 1-1 Asahidai, Nomi 923-1292, Japan. ${ }^{3}$ Laboratory for Applied Ontology (LOA), ISTC-CNR, via alla Cascata 56/C, Povo, 38123 Trento, Italy.

Received: 27 February 2019 Accepted: 9 October 2019

Published online: 18 December 2019

References

Basque, J. (2004). Le transfert d'apprentissage: Qu'en disent les contextualistes. In A. Presseau et M. Frenay, Le transfert des apprentissages, comprendre pour mieux intervenir (pp. 49-76).

Bates, A. W., Bates, T., \& Sangra, A. (2011). Managing technology in higher education: Strategies for transforming teaching and learning. Wiley. 
Bazire, M., \& Brézillon, P. (2005). Understanding context before using it. In International and Interdisciplinary Conference on Modeling and Using Context (pp. 29-40). Springer.

Blanchard, E. G., Mizoguchi, R., \& Lajoie, S. P. (2010). Structuring the cultural domain with an upper ontology of culture. In The handbook of research on culturally-aware information technology: Perspectives and models (pp. 179-212).

Brézillon, P. (2002). Modeling and using context: Past, present and future. Rapport de Recherche du LIP6 2002/010. France: Université Paris 6.

Chandrasekaran, B., Josephson, J. R., \& Benjamins, V. R. (1999). What are ontologies, and why do we need them? IEEE Intelligent Systems, 1, 20-26.

Collis, B., \& Moonen, J. (2012). Flexible learning in a digital world: Experiences and expectations. Routledge.

Côté, L., \& Hudon, E. (2005). L'approche centrée sur le patient: Diverses manières d'offrir des soins de qualité. In C. Richard \& M. T. Lussier (Eds.), La communication professionnelle en santé, ERPI (pp. 145-164) (sous la dir. de).

Edmundson, A. (2007). The cultural adaptation process (CAP) model: Designing e-learning for another culture. In Globalized Elearning cultural challenges (pp. 267-290).

Gilbert, J. K., Bulte, A. M., \& Pilot, A. (2011). Concept development and transfer in context-based science education. International Journal of Science Education, 33(6), 817-837.

Gros, B., \& Maina, M. (2015). The future of ubiquitous learning: Learning designs for emerging pedagogies. Springer.

Gruber, T. R. (1993). A translation approach to portable ontology specifications. Knowledge Acquisition, 5(2), 199-220.

Hayashi, Y., Bourdeau, J., \& Mizoguchi, R. (2009). Using ontological engineering to organize learning/instructional theories and build a theory-aware authoring system. International Journal of Artificial Intelligence in Education, 19(2), 211-252.

Leitner, P., Khalil, M., \& Ebner, M. (2017). Learning analytics in higher education —A literature review. In Learning analytics: Fundaments, applications, and trends (pp. 1-23). Springer.

Maina, M. F., \& González, I. G. (2016). Articulating personal pedagogies through learning ecologies. In The future of ubiquitous learning (pp. 73-94). Springer.

Maseleno, A., Sabani, N., Huda, M., Ahmad, R., Jasmi, K. A., \& Basiron, B. (2018). Demystifying learning analytics in personalised learning. International Journal of Engineering \& Technology, 7(3), 1124-1129.

Mizoguchi, R. (2003). Part 1: Introduction to ontological engineering. New Generation Computing, 21(4), 365-384.

Mizoguchi, R. (2010). YAMATO: Yet another more advanced top-level ontology. In Proceedings of the sixth Australasian ontology workshop (pp. 1-16).

Mizoguchi, R., Sunagawa, E., Kozaki, K., \& Kitamura, Y. (2007). The model of roles within an ontology development tool: Hozo. Applied Ontology, 2(2), 159-179.

Rogers, P. C., Graham, C. R., \& Mayes, C. T. (2007). Cultural competence and instructional design: Exploration research into the delivery of online instruction cross-culturally. Educational Technology Research and Development, 55(2), 197-217.

Savard, I. (2014). Modélisation des connaissances pour un design pédagogique intégrant les variables culturelles. Télé-université.

Savard, I., Bourdeau, J., \& Paquette, G. (2008). Cultural variables in the building of pedagogical scenarios: The need for tools to help instructional designers. In CATS 2008: Workshop on Culturally-Aware Tutoring Systems, 83.

Savard, I., \& Mizoguchi, R. (2016). Ontology of culture: A procedural approach for cultural adaptation in ITSs. In Presented at the 24th conference on computers in education (ICCE), Mumbai, India.

Savard, I., Paquette, G., \& Bourdeau, J. (2014). An advisor system for cultural adaptation in instructional design. In Proceedings of the Fifth International Workshop on Culturally-Aware Tutoring Systems (CATS2014).

Spencer-Oatey, H. (2004). Culturally speaking: Managing rapport through talk across cultures. A\&C Black.

Stewart, M. (2003). Patient-centered medicine: Transforming the clinical method. Radcliffe Publishing.

Subramony, D. P. (2011). Socio-cultural issues in educational technology integration. Colleagues, 6(1), 10

Subramony, D. P. (2017). Revisiting instructional technologists' inattention to issues of cultural diversity among stakeholders. In Culture, learning, and technology (pp. 28-43). Routledge.

Tardif, J. (2006). L'évaluation des compétences. In Documenter Le Parcours de Développement. Montréal: Chenelière Éducation.

Tardif, J., \& Meirieu, P. (1996). Stratégie pour favoriser le transfert des connaissances. Vie Pédagogique, 98(7), 4-7.

Williams, R., Karousou, R., \& Mackness, J. (2011). Emergent learning and learning ecologies in Web 2.0. The International Review of Research in Open and Distributed Learning, 12(3), 39-59.

Young, P. A. (2008). The culture based model: Constructing a model of culture. Journal of Educational Technology \& Society, 11(2), 107.

\section{Publisher's Note}

Springer Nature remains neutral with regard to jurisdictional claims in published maps and institutional affiliations.

\section{Submit your manuscript to a SpringerOpen ${ }^{\circ}$ journal and benefit from:}

- Convenient online submission

- Rigorous peer review

- Open access: articles freely available online

- High visibility within the field

- Retaining the copyright to your article

Submit your next manuscript at $\mathbf{s p r i n g e r o p e n . c o m ~}$ 